\title{
Problem Orientated Medical Records
}

\author{
Lt Col S Bernstein* \\ $M B, F R C G P$, RAMC \\ New Territories Group Practice, Hong Kong
}

SUMMARY: Problem orientated medical records will accommodate and integrate information about minor: and major problems, allow rapid updating of information and better communication between health agencies. and primary care team members. They will allow colleagues to retrieve information and assess patient ${ }^{\circ}$ problems, enable better co-ordination to occur between patient investigation and treatment, and rationalise decision making.

In Part Two a method of medical recording is described using various coloured forms. Problems encount-⿳⺈⿴囗十 ered and suggested solutions have been made. It is felt that the introduction of this method will lead to improved medical care for patients.

\section{Introduction}

In future, records in general practice will need to communicate the patients' problems to different members of the practice team rather than act as an aide memoire for one doctor.

In traditional medical records the information is often stored in a haphazard way. The patients' problems are frequently difficult to define or recall and clinical data may also be lost.

For service families in particular and also service personnel, due to turbulence both for patients and doctors, problem orientated medical records are more important than for patients in the National Health Service who are, on the whole, a relatively static population, for years attend the same doctor.

The article is in two parts. Part One describes problem orientated medical records. Part Two discusses some of the difficulties encountered in formulating these records when a trial scheme was carried out in 1976-77.

\section{PART I}

Problem orientated medical records (POMR) have four clearly defined components with a fifth as a refinement; each will be discussed. All components of POMR were colour coded as shown in brackets against each component.

\section{Basic Information Package or Data Base (Green)}

This is a clearly recognisable sheet carrying personal information about the patient which is needed from time to time but not at every consultation. The following information should be contained on a data base. Table I.

*Now Colonel, SMO Chatham Garrison

\section{Table I}

Data Base

Fixed Data

Fixed Data

\{ Slowly Changing Data $\stackrel{?}{+}$ 윽

$\left(\begin{array}{l}\text { Sex } \\ \text { Date of birth } \\ \text { Previous illnes }\end{array}\right.$

Frevious illnesse

Diseases where there

is familial component

Blood group

( Marital Status

Occupation (S)

Slowly Changing Data

Type of accommodation

Results of screening

Tests BCG, Cervical

Cytology

The Problem List (Pink)

This sets down all the doctor's cause of concern about the patient. A colleague picking up the recordo can see in 10 seconds what the doctor is concerned about in the patient's physical and mental health.

The most important characteristic of the problem list is that it allows the doctor to show his concern about the patient in diagnostic terms, dyspepsia rather than ?? peptic ulcer. Table II.

Table II

\begin{tabular}{|c|c|c|c|}
\hline No & $\begin{array}{l}\text { Date } \\
\text { First } \\
\text { Noted }\end{array}$ & $\begin{array}{c}\text { Active } \\
\text { Problem }\end{array}$ & $\begin{array}{c}\text { Inactive } \\
\text { or } \\
\text { Resolved }\end{array}$ \\
\hline 1 & $12 / 2 / 74$ & Dyspepsia & \\
\hline 1 & $18 / 4 / 74$ & $\begin{array}{c}\text { Duodenal } \\
\text { Ulcer } \\
\text { (Confirmed } \\
\text { by BA meal) }\end{array}$ & . \\
\hline
\end{tabular}


The next important characteristic of the problem list is that it acts as a cue for "action." The doctor is prompted to try and deal with all causes for concern not just the presenting complaint.

It is a basic rule of problem orientated medicine that the doctor must peruse the problem list at the beginning of every patient contact. $\mathrm{He}$ then will decide what problem or problems to discuss at the consultation irrespective of the present complaint.

When problems cease to be active they are marked inactive or resolved on a problem orientated summary card. The question to be decided is "what is a problem?" A problem can be:

(a) Diagnostic Disease - a disease with a confirmed diagnosis including social and psychiatric conditions.

(b) Sub Diagnostic Disease - a disease where signs and symptoms are not yet part of a confirmed diagnosis, for example dyspepsia. Laboratory findings may not be diagnostic.

(c) Minor Problems - Examples of these problems are, tonsillitis, cystitis, cough, etc. For instance if a child presents with one attack of tonsillitis this is noted on the progress notes as a minor problem. If the child gets tonsillitis six times yearly then it is worthy of entering this on the problem list. Identified problems on the list are dated and numbered and the number of the problem is entered into the clinical notes at the side of any consultation about the problem. This gives an index and allows all consultations about one disease to be easily resolved.

As problems are resolved they are marked off into the inactive or resolved part of the problem list so the problem list also becomes an up to date summary of past medical history.

\section{Clinical or Progress Notes (Buff)}

The forms used for these are the EC7 and EC8. The notes comprise the record of the patients continuing care just as traditional notes do; the improvement is that each entry is headed by the number or title of the problem to which it refers and each entry is made in the order Subjective (S), Objective (O). Analysis (A) and Plan (P). One additional refinement is the doctor writes down on the standard forms EC7 and EC8 what the patient has been told by him at the time.

It is doubtful whether older members in the general practitioner sphere would be willing to rethink on their progress note taking. It is something that should be an ideal to strive for in the general practice training of trainees and younger doctors entering general practice.

\section{Drug Record Cards (Yellow)}

These are especially useful for the chronic cases, bronchitics, hypertensives, arthritics etc as apart from the fact that a consultation is not always required it shows the doctor easily if the patient is adhering to his or her drug regime, and the card can be taken by the patient when he or she goes on holiday. The card should always be in the possession of the patient in the event of any emergency.

\section{Flow Charts (Various Colours)}

I do not consider this as an essential part of problem orientated medical records but as an aide memoire to the doctor and very valuable for trainees. The conditions particularly which lend themselves to flow charts are diabetes and hypertension.

Before concluding Part One it is necessary to mention that irrelevant letters and reports should be discarded from medical records. This can easily make a fat medical envelope thin.

Examples of what should be discarded are referral to gynaecological out patients - nil found, blood ${ }_{0}^{\circ}$ tests which are normal and routine follow up reportson from out patients such as "patient continues to improve, carry on with the same treatment, see in one month."

\section{PART II}

During a six month period 1976 to 1977 a total of 536 patients were asked to complete a data base. Only $43(8 \%)$ did not return this form and onee patient refused, commenting that the information? was "much too personal for the doctor to know!"

All staff of the MRS were fully briefed and shown the various forms to be used.

The problems encountered can be summarised under four headings:

Time: The average time taken to peruse medical documents, extract relvant information and initiate forms was 20 minutes. The current $F$ Med 2 and F Med 4 are equivalent to a data base so $I$ feel for serving personnel it is not necessary to intro. duce new forms. For children under five years of age unless there is a special problem such as asthma the same applies.

Non Availability of Clinical Notes: This was the main difficulty. Dependants' old notes took an average of eight months to arrive from the United Kingdom - if they arrived at all! There must be discussion with the DHSS on this point. The present system of acquiring notes is labour intensive and frustrating to doctors, patients and clerical staff.

What is a Problem Medically: This can only be decided on a practice basis. In our practice it was decided for example that four attacks of tonsillitis, 
one proved urinary tract infection in a male, two in a female, would be entered on the problem list.

Discarding of Letters and Reports: This perhaps was the subject which engendered most discussion. The younger doctors in the practice were against discarding any notes. It was agreed after much discussion that many reports are irrelevant though all documents relating to any accident were retained for medico-legal reasons. The discarding of any medical notes will cause anguish to a lot of doctors, but it is an integral part of good note keeping.

\section{How can these Problems be Resolved?}

Time: If one takes a service group practice of 6000 personnel including dependants with 3 doctors then by excluding service personnel $(50 \%)$, children under five years $(12 \%)$ one is left with 2,300 (38\%) notes to peruse. If each doctor spends one hour daily (three sets of notes) on this exercise then within one year all the notes can be converted. One learns so much about a patient by this exercise that this alone makes the procedure worthwhile.

Non Availability of Clinical Notes: I believe that dependants, particularly those going overseas should be either given their notes sealed to take with them or their notes sent with their husbands to the next 3 unit. I realise the legal implications of this but it $\$$ is only the outside envelope which is DHSS property not the clinical notes so why not extract these?

\section{Conclusion}

This article is intended to show a method of $\bar{C}$ record keeping which, if it could be introduced into service medical practice, would lead to better notes? and standardisation. No method of clinical recording $\varrho$ is ideal, but the present state of medical documenta- $ळ$ tion is deplorable and any new system introduced $\vec{\circ}$ could only benefit patients and doctors.

It is time that we in the services took the lead $\vec{\omega}$ in the formulation of problem orientated medical records. This can be achieved only if all practices start to sort their medical notes on a given date.

It will be argued that we will be doing this work $\vec{N}$ for the DHSS; whether this is true or not it will help? us as service doctors to provide a better servige N for our patients and 1 believe an overall improvê ment in our medical care, and surely these are goaffo towards which we must aim. 